\title{
Research Paper: The Effect of Different Phases of the Menstrual Cycle on Respiratory Indices in Women With Primary Dysmenorrhea
}

\author{
Fatemeh Oraki $^{1}$, Majid Ravanbakhsh ${ }^{1 *}$, Mayam Saadat ${ }^{1}$, Simin $_{\text {Montazari }}{ }^{2} \mathrm{C}$ \\ 1. Musculoskeletal Rehabilitation Research Center, Ahvaz Jundishapur University of Medical Sciences, Ahvaz, Iran. \\ 2. Department of Nursing and Midwifery, Health Research Institute, Midwifery, Ahvaz Jundishapur University of Medical Sciences, Ahvaz, Iran.
}

\begin{tabular}{|l|l|}
\hline $\begin{array}{l}\text { Use your device toscan } \\
\text { and read the article online }\end{array}$ & $\begin{array}{l}\text { Cittation: Oraki F, Ravanbakhsh M, Saadat M, Montazari S. The Effect of Different Phases of the Menstrual Cycle on Respi- } \\
\text { ratory Indices in Women With Primary Dysmenorrhea. Journal of Modern Rehabilitation. 2019; 13(4):185-192. http://dx.doi. } \\
\text { org/10.32598/JMR.13.4.185 } \\
\text { def" http://dx.doi.org/10.32598/JMR.13.4.185 }\end{array}$
\end{tabular}

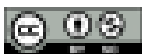

Article info:

Received: 10 Apr 2019

Accepted: 25 Aug 2019

Available Online: 01 Oct 2019

\section{Keywords:}

Primary dysmenorrhea,

Menstruation cycle,

Respiratory pattern, respiratory

index, Capnography

\section{ABSTRACT}

Introduction: Physiological changes during the menstrual cycle in women with primary dysmenorrhea may affect their respiratory system, so this study aimed to examine various respiratory parameters in three phases of the menstrual cycle in these women.

Materials and Methods: This study was conducted on 15 women with dysmenorrhea aged 18-25 years. The respiratory parameters were measured using a capnograph during the menstrual phase (MP; on days 3 or 4), follicular phase (FP; on days 10 or 11), and luteal phase (LP; on days 20 or 21).

Results: The results of this study showed a significant difference in end-tidal $\mathrm{CO}_{2}$ pressure in the follicular and luteal phase with that in the menstrual phase $(\mathrm{P}<0.01)$. Also, the respiration rate and oxygen saturation showed a significant difference in different phases of menstruation $(\mathrm{P}<0.01)$.

Conclusion: The results of this study indicated that respiratory indices differ in various phases of the menstrual cycle in women with primary dysmenorrhea, which seems to be due to pain during the menstrual cycle and increased progesterone levels in the luteal phase.

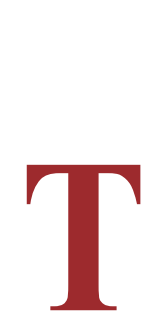

\section{Introduction}

he menstrual cycle is not only an integral part of women's fertility but a vital sign of a woman's health, too. One of the most common complaints of women during this cycle is dysmenorrhea or painful menstruation. Dysmenorrhea is divided into two types of primary and secondary $[1,2]$. Primary dysmenorrhea refers to chronic and periodic pelvic pains in the absence of any proven pelvic disease and begins with menstrual hemorrhage or even before it and may continue for up to 72 hours. In secondary dysmenorrhea, the pain is caused by an abnormal pathology or abnormal anatomy of the pelvis [3-6].

Many menstrual symptoms affect women's quality of life, interfering with their education, work, personal and family relationships, and in many cases, lead to increased medical care, reduced work efficiency, and 
absence from the workplace or university [3-7]. In the United States, $14 \%$ of adolescents with dysmenorrhea are reported to be frequently absent from school, and dysmenorrhea is responsible for the loss of 600 million working hours and 2 billion US dollars per year [8].

Different methods are currently used to control dysmenorrhea that grouped into two categories: medical and non-medical. The medical approach, such as administration of prostaglandin synthase inhibitors, can lead to gastrointestinal ulceration, nausea, malabsorption, diarrhea, and occasional fatigue [9-11]. Therefore, non-medical approaches, such as respiratory rehabilitation, can be a low-cost, convenient, and accessible option with no side effects for reducing pain and improving symptoms and mood. But for the use of respiratory techniques, we should know the changes in respiratory indices in these women.

The physiological changes during the menstrual cycle in women with primary dysmenorrhea may alter the respiratory system, which can increase pain perception and even reduce the pain tolerance threshold. Because of pelvic and back pain in dysmenorrhea, 70\%-80\% of the muscles in these areas are affected, and owning to the synergy of these muscles with the diaphragm, they eventually disrupt breathing pattern [12]. Subjects with dysmenorrhea often feel anxious and stressed because of experiencing pain. Chronic psychological stresses and increased mental pressure can interfere with the pattern of respiration. Studies have shown that mental stress increases the tone of the diaphragm and immobilizes it. Also, the fluctuations in arterial carbon dioxide pressure that occur after an increase in respiratory rate can have a disturbing effect on the automated nervous system, which causes the sympathetic system to predominate $[13,14]$. Besides, female sex hormones can affect respiration rates [15-17].

Several studies showed the effects of the different phases of the menstrual cycle on lung function, such as forced vital capacity and forced expiratory volume in 1 second in healthy, overweight, and obese female subjects and women with asthma [18-21]. However, to the best of our knowledge, no study has investigated the effect of different phases of the menstrual cycle on respiratory indices in women with primary dysmenorrhea. Therefore, this study was conducted to examine the respiratory indices of women with primary dysmenorrhea during different (menstrual, follicular, and luteal) phases of the menstrual cycle.

\section{Methods}

This research is a cross-sectional study conducted in Ahvaz City, Iran, in 2017 to investigate the changes in breathing indices during the three phases of menstruation among women with primary dysmenorrhea. We started the study by inviting women who had primary dysmenorrhea with a regular menstrual cycle (28-30 days) and a menstrual period of 3 to 8 days. They all experienced severe pain during menstruation ranging from 7 to 10 , according to the visual analog scale. Individuals with respiratory and cardiovascular diseases, secondary dysmenorrhea, and pregnancy, those who smoked cigarettes, consumed alcohol, and took painkillers, pain relief medication, or contraceptives, were excluded from the study. A randomized sampling method was used to study the list of students at the female dormitories of Ahvaz Jundishapur University of Medical Sciences who met the inclusion criteria. The sample size was calculated to be 14, using the G-power sample model 3.0.10 software. In this regard, we took into account the threeway repeated measures of variance analysis, with an effect size of 0.4 , the significance level of 0.05 , and the statistical power of $85 \%$.

Initially, the subjects were referred to a gynecologis to determine the type of their dysmenorrhea. To record the body temperature from the first day to the last day of the menstrual cycle, we gave an oral thermometer to the subjects who had to put it under their tongue for three minutes in the morning before getting out of bed and then record the temperature in a chart. If a subject had primary dysmenorrhea, ovulation should have occurred, and on the ovulation day, her temperature should increase half degree. After gynecologists' confirmation and giving appropriate body temperature charts, we began collecting and recording background information of the subjects. Participants signed written consent before the study. Also, the investigator explained the study procedure to women.

The information on the respiratory system was collected using a capnograph device. This device is manufactured by Viamed Company (2500, England) belonging to the laboratory of the musculoskeletal research center of rehabilitation faculty. This machine instantaneously measures the amount of gas exchanged during breathing and records it on a curve. Respiratory parameters were recorded for each individual in three phases: menstrual (the third or fourth day of the menstrual cycle), follicular phase (the 10th or 11th day of the menstrual cycle), and luteal phase (the $20^{\text {th }}$ or $21^{\text {st }}$ day of the menstrual cycle). 
In the process of recording information, the individuals were provided with detailed descriptions of how the research was carried out and the steps taken. The sampling time was from $9 \mathrm{AM}$ to $11 \mathrm{AM}$. Before recording the information of each subject and each time, the capnography system was calibrated. The person was asked to sit on a comfortable chair, and then a nasal cannula which was attached to the device was placed in the nose of the individual. The subjects were told that this test had no risk or side effects for them. They were also asked to breathe only through the nose for 3 to 5 minutes and avoid talking during the test. The percentage of oxygen saturation and heart rate was measured by a pulse oximeter connected to the fingertips of the subjects.

Owning to the effect of temperature on breathing, the temperature of the testing environment was controlled. The primary data obtained from the device used in this study involved the measurement of the end-tidal carbon dioxide $\left(\mathrm{ET}-\mathrm{CO}_{2}\right)$ pressure levels within the standard range of $5 \%$ to $6 \%$, respiration rate within the usual range of 12 to 18 breaths per minute, and oxygen saturation percentage within the standard range $95 \%$ to $100 \%$. At the end of the data logging, we extracted the file from the device, converted the output of the device into an Excel file, and conducted the statistical analysis.

\section{Statistical analysis}

Statistical calculations were done in SPSS V. 23. At first, the distribution of variables was examined by the Kolmogorov-Smirnov (K-S) test, which confirmed the normal distribution of the data. Repeated measures of variance (ANOVA) were used to investigate the effect of menstruation on respiratory indices at three times. An additional Least Significant Difference (LSD) test was used to examine every two different states. P values less than 0.05 were considered as significant in this study.

\section{Results}

34 participants assessed for eligibility, 15 subjects included that theyhad inclusion criteria. Demographic and clinical characteristics of the participants are shown in Table 1. The Kolmogorov-Smirnov test showed normal distribution of the respiratory indices of ET- $\mathrm{CO}_{2}$ pressure, respiration rate, and oxygen saturation percentage. The results of the repeated measures of ANOVA test were significant for ET- $\mathrm{CO}_{2}$, respiration rate, and oxygen saturation percentage. Table 2 presents the mean and standard deviation of parameters at three different phases of the menstrual cycle.

The results of the LSD test in two different states showed that the menstrual phase was significantly different between the follicular and luteal phases in terms of expiratory carbon dioxide pressure indices, respiration rate, and oxygen saturation rate $(\mathrm{P}<0.01)$, but there was no significant difference in respiration rate and carbon dioxide pressure between the follicular phase and the luteal phase. The results of the present study also indicate that the expiratory carbon dioxide pressure index was the lowest during the menstrual phase as compared with that in the luteal and follicular phase (Figure 1). The respiratory rate index was the highest in the menstrual phase (Figure 2). Finally, the oxygen saturation index was within the normal range during all phases.

\section{Discussion}

The purpose of this study was to investigate important respiratory indices in women with primary dysmenorrhea in different phases of menstruation. The results of this study showed that the amount of carbon dioxide pressure in the follicular phase significantly increased compared with that in the menstrual phase, and it decreased significantly in the luteal phase compared with the menstrual phase. Reduced expiratory carbon dioxide

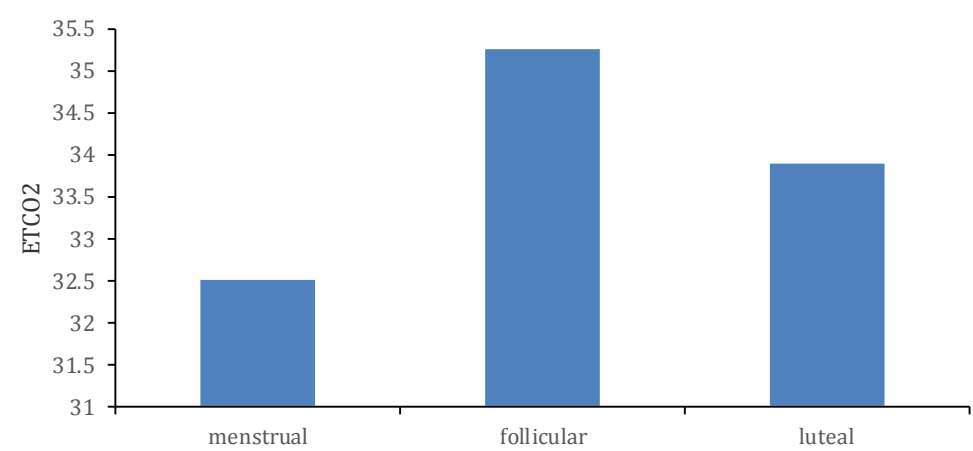

Figure 1. Changes in end-tidal carbon dioxide during the menstrual cycle 
Table 1. Demographic information of women with primary dysmenorrhea

\begin{tabular}{ccccc}
\hline Characteristics & Min. & Max. & Mean \pm SD \\
\hline Age $(\mathrm{y})$ & 18 & 25 & $21.4 \pm 2.49$ \\
Height $(\mathrm{cm})$ & 155 & 178 & $165.40 \pm 8.33$ \\
Weight $(\mathrm{kg})$ & 55 & 75.85 & $65.99 \pm 8.42$ \\
\hline Body mass index $\left(\mathrm{kg} / \mathrm{m}^{2}\right)$ & 22.09 & 28 & $23.93 \pm 1.63$ \\
\hline Menstrual cycle (day) & 28 & 30 & $28.66 \pm 0.97$ \\
\hline Menstruation (day) & 3 & 7 & $5.26 \pm 1.83$ \\
\hline Pain intensity (cm) & 7 & 10 & $8.66 \pm 1.17$ \\
\hline
\end{tabular}

Table 2. Respiratory indices across different phases of the menstrual cycle

\begin{tabular}{|c|c|c|c|c|}
\hline \multirow{2}{*}{ Variable } & \multicolumn{3}{|c|}{ Mean $\pm S D(95 \% \mathrm{Cl})$} & \multirow{2}{*}{$\mathbf{P}$} \\
\hline & Menstrual & Follicular & Luteal & \\
\hline $\mathrm{ET}-\mathrm{CO}_{2}(\mathrm{mmHg})$ & $\begin{array}{c}32.50 \pm 0.29 \\
\text { (31.77 to } 33.67)\end{array}$ & $\begin{array}{c}35.27 \pm 1.17 \\
\text { (34.27to } 36.56)\end{array}$ & $\begin{array}{c}33.89 \pm 1.16 \\
(32.97 \text { to } 34.26)\end{array}$ & $<0.01$ \\
\hline $\mathrm{SPO}_{2}$ (percent) & $\begin{array}{c}98.23 \pm 0.99 \\
\text { (97.77 to } 98.67)\end{array}$ & $\begin{array}{c}98.78 \pm 0.59 \\
\text { (98.72to 98.84) }\end{array}$ & $\begin{array}{c}97.63 \pm 0.99 \\
\text { (97.21 to } 98.06)\end{array}$ & $<0.01$ \\
\hline RR (breaths per minute) & $\begin{array}{c}24.05 \pm 3.96 \\
\text { (21.70 to } 24.68 \text { ) }\end{array}$ & $\begin{array}{c}15.35 \pm 1.90 \\
(14.29 \text { to } 16.40)\end{array}$ & $\begin{array}{c}17.03 \pm 2.19 \\
(15.82 \text { to } 18.24)\end{array}$ & $<0.01$ \\
\hline
\end{tabular}

$J M R$

ET- $\mathrm{CO}_{2}$ : End-tidal carbon dioxide; $\mathrm{SpO}_{2}$ : Peripheral capillary oxygen saturation; RR: Respiratory rate

pressure in the luteal phase compared with the other two phases can be attributed to increased progesterone secretion at this phase [22].

The concentration of progesterone reaches its maximum level 5 days after ovulation (the luteal phase), and this level is maintained for up to 7 days. The metabolic acidosis created by the increased concentration of this hormone results in compensatory respiratory responses that appear as an increase in the number and depth of respiration [23]. The effect of progesterone on central and peripheral respiratory centers increases their sensitivity

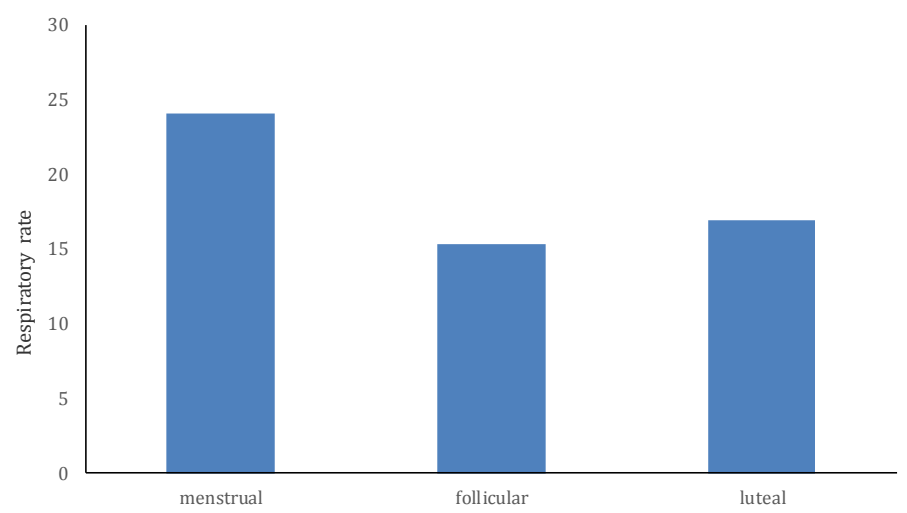

Figure 2. Changes in the respiratory rate during the menstrual cycle 
and the number and extent of breathing and ultimately leads to more carbon dioxide excretion and reduced exhaust-gas $\mathrm{CO}_{2}$ pressure [24]. Also, the increased level of progesterone hormone during pregnancy has the same effect, namely increasing the sensitivity of respiratory centers to carbon dioxide and reducing carbon dioxide pressure [25].

In agreement with the results of this study, Slatkovska et al. found a decrease in arterial carbon dioxide pressure in the luteal phase compared with the follicular phase, although their research was done on normal menopausal women [26]. Also, Das studied the respiratory indices of 40 healthy women and reported increased respiratory time and flow in the luteal phase [22]. McLaughlin and Goldsmith conducted a study on 24 patients with pelvic and back pain (70\%-80\% of women with dysmenorrhea have back and pelvic pain) and reported reduced carbon dioxide pressure in these patients [27]. A hyperventilation pattern has been shown in the luteal phase in healthy women and those with dysmenorrhea.

Also, the results of this study showed a higher respiratory rate in the menstrual phase, as opposed to the follicular and luteal phases (painless phases). The increase in the respiration rate in the menstrual phase can be attributed to the presence of pain stimuli. The relationship between pain and respiratory indices has been shown in previous studies. A review article reported that in the presence of painful stimuli, healthy people have deeper and stronger respiration [8]. Severe pain increases the secretion of catecholamines such as epinephrine and norepinephrine, which stimulate alpha receptors, leading to vascular contraction, decreased uterine blood flow, and increased blood pressure in the individual.

This, in turn, leads to an increase in the rate of respiration and the exhaustion of carbon dioxide. Consistent with the results of the present study, Girija et al. examined 40 women aged 18-22 years with a regular menstrual cycle. They found that respiratory rate during the luteal phase increased after an increase in progesterone levels and sensitivity of respiratory centers to carbon dioxide [28]. However, Das TK did not report significant changes in respiratory rate indices in 40 women in different phases of the menstrual cycle, which is not consistent with the results of the present study [22]. The reason for this difference is probably due to the presence of pain in the subjects participating in our research. The use of respiratory techniques in controlling pain is one of the approaches that has recently replaced the use of harmful drugs [8].
The oxygen saturation index was within the normal range in all three phases. Confirming our study, McLaughlin et al. found that the majority of respiratory illnesses did not affect oxygen saturation [29].

The main limitations of this study were investigating the respiratory pattern of people in a non-functional sitting state, the extreme sensitivity of the capnography device to the humidity of the environment, and the need for the replacement of the adapter. Therefore, future studies are recommended to study people in a functional state or during dynamic activity. Future research can also investigate the effect of respiratory interventions on the respiratory pattern and the measurement indices of vital blood gases in women with primary dysmenorrhea. What makes the present study unique, however, is the fact that it is the first study to investigate women with primary dysmenorrhea during their menstrual cycle.

\section{Conclusion}

The results of this study indicate that respiratory indices differ in various phases of the menstrual cycle in women with primary dysmenorrhea, which seems to be due to pain during the menstrual cycle and increased progesterone levels in the luteal phase. Considering the adverse influence of pain on respiratory indices, a pain relief intervention can be provided by physical therapists. Physiotherapy can manage back pain based on evidence-based guidelines and systematic reviews.

\section{Ethical Considerations}

\section{Compliance with ethical guidelines}

The Ethics Committee of Ahvaz Jundishapur University of Medical Sciences, Ahvaz City, Iran approved this study (Approval number: U_96132).

\section{Funding}

This research did not receive any specific grant from funding agencies in the public, commercial, or not-forprofit sectors.

\section{Authors contributions}

All authors contributed in preparing this paper.

\section{Conflict of interest}

The authors declared no conflict of interest. 


\section{References}

[1] Dasharathy SS, Mumford SL, Pollack AZ, Perkins NJ, Mattison DR, Wactawski-Wende J, et al. Menstrual bleeding patterns among regularly menstruating women. American Journal of Epidemiology. 2012; 175(6):536-45. [DOI:10.1093/aje/ kwr356] [PMID] [PMCID]

[2] Paramsothy P. Menstrual cycle patterns and their determinants during the menopausal transition among a multiethnic cohort of women [PhD. dissertation]. Ann Arbor, MI: The University of Michigan; 2012. https://deepblue.lib.umich.edu/ handle/2027.42/94090

[3] French L. Dysmenorrhea in adolescents: Diagnosis and treatment. Paediatric Drugs. 2008; 10(1):1-7. [DOI:10.2165/00148581200810010-00001] [PMID]

[4] Ortiz MI, Cortés-Márquez SK, Romero-Quezada LC, Murguía-Cánovas G, Jaramillo-Díaz AP. Effect of a physiotherapy program in women with primary dysmenorrhea. European Journal of Obstetrics \& Gynecology and Reproductive Biology. 2015; 194:24-9. [DOI:10.1016/j.ejogrb.2015.08.008] [PMID]

[5] Unsal A, Ayranci U, Tozun M, Arslan G, Calik E. Prevalence of dysmenorrhea and its effect on quality of life among a group of female university students. Upsala Journal of Medical Sciences. 2010; 115(2):138-45. [DOI:10.3109/03009730903457218] [PMID] [PMCID]

[6] Vlachou E, Owens DA, Lavdaniti M, Kalemikerakis J, Evagelou E, Margari N, et al. Prevalence, wellbeing, and symptoms of dysmenorrhea among university nursing students in Greece. Diseases. 2019; 7(1):pii:E5. [DOI:10.3390/diseases7010005] [PMID] [PMCID]

[7] Kahyaoglu Sut H, Mestogullari E. Effect of premenstrual syndrome on work-related quality of life in Turkish nurses. Safety and Health at Work. 2016; 7(1):78-82. [DOI:10.1016/j. shaw.2015.09.001] [PMID] [PMCID]

[8] Copeland LJ, Jarrell JF. Textbook of gynecology. Philadelphia: Saunders; 2000. https://books.google.com/ books?id=XYyIQgAACAAJ\&dq

[9] Jafari H, Courtois I, Van den Bergh O, Vlaeyen JWS, Van Diest I. Pain and respiration: A systematic review. Pain. 2017; 158(6):995-1006. [DOI:10.1097/j.pain.0000000000000865] [PMID]

[10] Oladosu FA, Tu FF, Hellman KM. Nonsteroidal antiinflammatory drug resistance in dysmenorrhea: Epidemiology, causes, and treatment. American Journal of Obstetrics and Gynecology. 2018; 218(4):390-400. [DOI:10.1016/j.ajog.2017.08.108] [PMID] [PMCID]

[11] Damm T, Lamvu G, Carrillo J, Ouyang C, Feranec J. Continuous vs. cyclic combined hormonal contraceptives for treatment of dysmenorrhea: A systematic review. Contraception: $X$. 2019; 1:100002. [DOI:10.1016/j.conx.2019.100002]

[12] Perri MA, Halford E. Pain and faulty breathing: A pilot study. Journal of Bodywork and Movement Therapies. 2004; 8(4):297-306. [DOI:10.1016/S1360-8592(03)00085-8]

[13] Courtney R. The functions of breathing and its dysfunctions and their relationship to breathing therapy. International Journal of Osteopathic Medicine. 2009; 12(3):78-85. [DOI:10.1016/j. ijosm.2009.04.002]
[14] Yang L, Dun W, Li K, Yang J, Wang K, Liu H, et al. Altered amygdalar volume and functional connectivity in primary dysmenorrhea during the menstrual cycle. European Journal of Pain. 2019; 23(5):994-1005. [DOI:10.1002/ejp.1368] [PMID]

[15] Bayliss DA, Millhorn DE. Central neural mechanisms of progesterone action: Application to the respiratory system. Journal of Applied Physiology. 1992; 73(2):393-404. [DOI:10.1152/ jappl.1992.73.2.393] [PMID]

[16] Hannhart B, Pickett CK, Moore LG. Effects of estrogen and progesterone on carotid body neural output responsiveness to hypoxia. Journal of Applied Physiology. 1990; 68(5):1909-16. [DOI:10.1152/jappl.1990.68.5.1909] [PMID]

[17] Behan M, Wenninger JM. Sex steroidal hormones and respiratory control. Respiratory Physiology \& Neurobiology. 2008; 164(1-2):213-21. [DOI:10.1016/j.resp.2008.06.006] [PMID] [PMCID]

[18] Saperova E, Dimitriev D. Pulmonary functions in different phases of menstrual cycle. The FASEB Journal. 2013; 27(Suppl 1). [DOI:10.1289/isee.2013.P-3-11-10]

[19] Kaur H, Kohli PG, Arora R, Maini S. Effect of different phases of menstrual cycle on pulmonary functions. Indian Journal of Basic and Applied Medical Research. 2015; 5(1):266-9. http:// ijbamr.com/pdf/December\%202015\%20266-269.pdf.pdf

[20] Farha S, Asosingh K, Laskowski D, Hammel J, Dweik RA, Wiedemann HP, et al. Effects of the menstrual cycle on lung function variables in women with asthma. American Journal of Respiratory and Critical Care Medicine. 2009; 180(4):304-10. [DOI:10.1164/rccm.200904-0497OC] [PMID] [PMCID]

[21] Samsudeen N, Rajagopalan A. Effect of different phases of menstrual cycle on cardio-respiratory efficiency in normal, overweight and obese female undergraduate students. Journal of Clinical and Diagnostic Research. 2016; 10(12):CC01-CC04. [DOI:10.7860/JCDR/2016/23080.8954] [PMID] [PMCID]

[22] Das TK. Effects of the menstrual cycle on timing and depth of breathing at rest. Indian Journal of Physiology and Pharmacology. 1998; 42(4):498-502. [PMID]

[23] England SJ, Farhi LE. Fluctuations in alveolar $\mathrm{CO} 2$ and in base excess during the menstrual cycle1. Respiration Physiology. 1976; 26(2):157-61. [DOI:10.1016/0034-5687(76)90093-1]

[24] Jamieson DJ, Steege JF. The prevalence of dysmenorrhea, dyspareunia, pelvic pain, and irritable bowel syndrome in primary care practices. Obstetrics \& Gynecology. 1996; 87(1):55-8. [DOI:10.1016/0029-7844(95)00360-6]

[25] Weinberger SE, Weiss ST, Cohen WR, Weiss JW, Johnson TS, Pregnancy and the lung. The American Review of Respiratory Disease. 1980; 121(3):559-81. [DOI:10.1164/arrd.1980.121.3.559] [PMID]

[26] Slatkovska L, Jensen D, Davies GA, Wolfe LA. Phasic menstrual cycle effects on the control of breathing in healthy women. Respiratory Physiology \& Neurobiology. 2006; 154(3):37988. [DOI:10.1016/j.resp.2006.01.011] [PMID]

[27] McLaughlin L, Goldsmith CH. Altered respiration in a case series of low back / pelvic pain patients. Paper presented at: 6th Interdisciplinary Word Congress on Low Back and Pelvic Pain. November 2007; Barcelona, Spain. https://www. fasciaresearch.com/literature/wc-low-back-and-pelvic-pain/ McLaughlin07.pdf 
[28] Girija B, Veeraiah S. Effect of different phases of menstrual cycle on physical working capacity in Indian population. Indian Journal of Physiology and Pharmacology. 2011; 55(2):1659. [PMID]

[29] McLaughlin L. Breathing evaluation and retraining in manual therapy. Journal of Bodywork and Movement Therapies. 2009; 13(3):276-82 [DOI:10.1016/j.jbmt.2009.01.005] [PMID] Ariosam ad eum ut magnihici sunt. 
This Page Intentionally Left Blank 